\title{
Influences of the Presence of a Tall Grounded Strike Object and an Upward Connecting Leader on Lightning Currents and Electromagnetic Fields
}

\author{
Yoshihiro Baba, Member, IEEE, and Vladimir A. Rakov, Fellow, IEEE
}

\begin{abstract}
Using a generalized transmission line model of the lightning return stroke, we have investigated the influences of the presence of a tall strike object and an upward connecting leader on the magnitude of lightning current and on associated electric and magnetic fields. For a typical subsequent lightning return stroke, the peak current at the bottom of a 100-m-high object is 1.5 times larger than the channel base peak current for the same strike to the flat ground, regardless of the presence of a 20 -m-long upward connecting leader, while the lightning peak current at the top of the strike object is not much different from the current in the absence of the object. The vertical electric field due to a lightning strike to a 100-m-high object $E_{z_{-} \text {tall }}$ is reduced relative to that due to the same strike to the flat ground $E_{z \text { flat }}$ at distances ranging from $30 \mathrm{~m}$ to $200 \mathrm{~m}$ from the object and enhanced at distances greater than $200 \mathrm{~m}$. The azimuthal magnetic field for the tall object case $\boldsymbol{H}_{\varphi \_ \text {tall }}$ is larger than that for the flat ground case $H_{\varphi}$ flat at any distance. Beyond about $3 \mathrm{~km}, E_{z_{-} \text {tall }} / E_{z_{-} \text {flat }}$ becomes insensitive to distance change and is equal to $\boldsymbol{H}_{\varphi_{-} \text {tall }} / \boldsymbol{H}_{\varphi \text { flat }}$.
\end{abstract}

Index Terms-Lightning, lightning return-stroke model, tall object, transmission line (TL) model, upward connecting leader.

\section{INTRODUCTION}

$\mathbf{R}$ ECENTLY, considerable attention has been attracted to the interaction of lightning with tall grounded strike objects [1]-[8]. When a transmissionline (TL)-type model of the lightning return stroke is generalized to include a tall grounded object, it is necessary to consider reflections, for which one needs to specify appropriate reflection coefficients at the top and bottom of the strike object. In this case, the use of an ideal current source at the channel attachment point, inserted in series between the lightning channel and strike object [1], does not allow one to obtain a self-consistent solution. This is because the ideal current source has infinitely large impedance, and hence, current waves reflected from ground cannot be directly transmitted to the lightning channel. In order to avoid the problem with lumped current sources, Rachidi et al. [4] have proposed a distributed shunt-current-source representation of the lightning channel, and Baba and Rakov [8] have proposed the TL model incorporating a lumped series voltage source at the junction point. Baba and Rakov [9] have also proposed the TL model of the lightning return stroke that is generalized to include a tall grounded strike object and an electrically long

Manuscript received May 12, 2006; revised September 9, 2006.

Y. Baba is with the Department of Electrical Engineering, Doshisha University, Kyoto 610-0321, Japan (e-mail: ybaba@mail.doshisha.ac.jp).

V. A. Rakov is with the Department of Electrical and Computer Engineering, University of Florida, Gainesville, FL 32611 USA (e-mail: rakov@ece.ufl.edu).

Digital Object Identifier 10.1109/TEMC.2007.908260 upward connecting leader. This latter model includes a lumped series voltage source at the junction between the descending and upward connecting leaders.

In this paper, using the TL model generalized to include a tall grounded strike object and an electrically long upward connecting leader, we investigate the influences of the presence of a tall strike object and an upward connecting leader on the magnitude of lightning current. We also examine influences on the vertical electric and azimuthal magnetic fields at ground level of the presence of a tall strike object, return-stroke propagation speed, return-stroke current rise-time, and the strike object height.

\section{TRANSMISSION LINE MODEL}

In this section, we will present expressions, derived by Baba and Rakov [9], for current along the lightning return-stroke channel, along a grounded strike object of height $h$ with or without an upward connecting leader of length $l$ launched from the object top, and along an upward connecting leader launched from ground.

\section{A. Lightning Strike to a Grounded Object Launching an Up- ward Connecting Leader $(h \neq 0, l \neq 0)$}

Fig. 1(a) shows a lightning strike to a grounded object of height $h$ launching an upward connecting leader of length $l$. It comprises three lossless uniform TLs representing the lightning channel (whose characteristic impedance is $Z_{\mathrm{ch}}$ both above and below the junction point between the descending leader and an upward connecting leader launched from the top of the grounded object) and the grounded object (whose characteristic impedance is $\left.Z_{\mathrm{ob}}\right)$, a lumped grounding impedance $\left(Z_{\mathrm{gr}}\right)$, and a lumped ideal (zero impedance) voltage source generating an arbitrary voltage waveform $V_{0}(h+l, t)$. The current propagation speed along the grounded object is assumed to be equal to the speed of light $c$ and to $v<c$ along the lightning channel. Note that there is no impedance discontinuity at the junction point between the descending and upward connecting leaders (current reflection coefficient at this junction point is zero). The current reflection coefficient at the bottom of the object $\left(\rho_{\mathrm{bot}}\right)$ and the current reflection coefficient at the top of the object for upward propagating waves $\left(\rho_{\text {top }}\right)$ are given by

$$
\rho_{\mathrm{bot}}=\frac{Z_{\mathrm{ob}}-Z_{\mathrm{gr}}}{Z_{\mathrm{ob}}+Z_{\mathrm{gr}}}, \quad \rho_{\mathrm{top}}=\frac{Z_{\mathrm{ob}}-Z_{\mathrm{ch}}}{Z_{\mathrm{ob}}+Z_{\mathrm{ch}}} .
$$

Baba and Rakov [10] have shown that a current wave suffers no attenuation when propagating downward from the apex of 


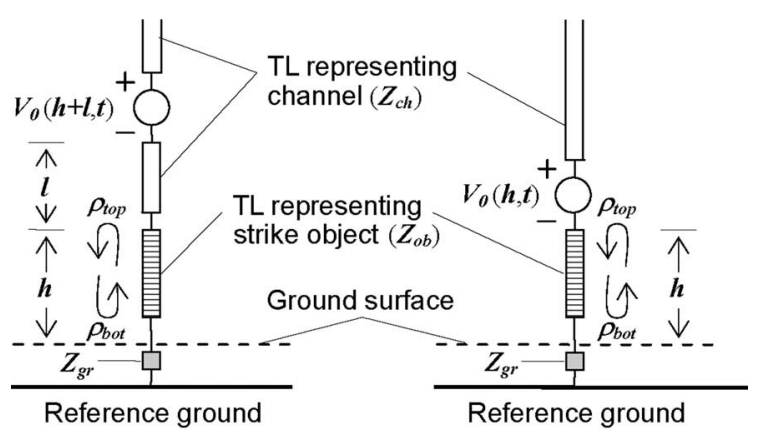

(a)

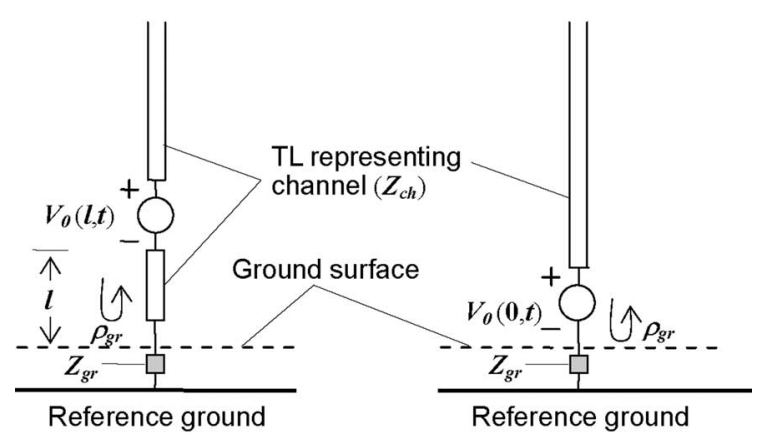

(c)

(d)

Fig. 1. Lightning strikes (a) to a grounded object of height $h$ launching an upward connecting leader of length $l$, (b) to a grounded object of height $h$ without an upward connecting leader, (c) to flat ground launching an upward connecting leader of length $l$, and (d) to flat ground without an upward connecting leader. All are represented by lossless TLs connected in series with a lumped voltage source generating an arbitrary voltage waveform, $V_{0}(h+l, t), V_{0}(h, t), V_{0}(l, t)$, and $V_{0}(0, t)$, respectively, and a lumped grounding impedance $\left(Z_{\mathrm{gr}}\right) . Z_{\mathrm{ch}}$ is the characteristic impedance of the TL representing the lightning channel both above and below the junction point between the descending and upward connecting leaders, $Z_{\mathrm{ob}}$ is that representing the grounded strike object, $\rho_{\text {top }}$ is the current reflection coefficient at the top of the strike object for upward propagating waves, $\rho_{\mathrm{bot}}$ is the current reflection coefficient at the bottom of the strike object, and $\rho_{\mathrm{gr}}$ is the current reflection coefficient at the channel base for the flat ground case.

a conical conductor to its base, but it suffers significant attenuation when propagating upward from the base of the conical conductor to its apex. Further, Baba and Rakov [11] have shown that a current wave, propagating downward from the top of a vertical uniform-thickness conductor such as a cylinder to its bottom, suffers attenuation particularly near the top, and a current wave, propagating upward from the bottom of the vertical uniform-thickness conductor to its top suffers attenuation, particularly near the bottom. Although these direction-dependent waveguiding properties of a vertical conductor are not considered in this paper, the representation of a vertical strike object by a lossless uniform TL terminated in a lumped grounding impedance shown in Fig. 1(a) and (b) (see also [12]) is justified in calculating lightning-generated magnetic fields and relatively distant electric fields. However, it may be inadequate for calculating electric fields in the immediate vicinity of strike object (see [10, Fig. 14]).

Currents at an arbitrary point $z^{\prime}$ along the lightning channel above the junction point between the descending and up- ward connecting leaders $\left(z^{\prime} \geq h+l\right)$, along the lightning channel below the junction point $\left(h \leq z^{\prime} \leq h+l\right)$, and along the strike object $\left(0 \leq z^{\prime} \leq h\right)$ are given by the following three equations:

$$
\begin{aligned}
I\left(z^{\prime}, t\right)= & \frac{1}{2} I_{\mathrm{sc}}\left(h+l, t-\frac{z^{\prime}-(h+l)}{v}\right) \\
& -\rho_{\mathrm{top}} \frac{1}{2} I_{\mathrm{sc}}\left(h+l, t-\frac{z^{\prime}-(h+l)-2 l}{v}\right) \\
& +\frac{1}{2}\left(1+\rho_{\mathrm{top}}\right)\left(1-\rho_{\mathrm{top}}\right) \sum_{n=1}^{\infty} \rho_{\mathrm{top}}^{n-1} \rho_{\mathrm{bot}}^{n} I_{\mathrm{sc}} \\
& \times\left(h+l, t-\frac{z^{\prime}-(h+l)-2 l}{v}-\frac{2 n h}{c}\right) \\
\text { for } & z^{\prime} \geq h+l
\end{aligned}
$$

(along the lightning channel above the junction point)

$$
\begin{aligned}
I\left(z^{\prime}, t\right)= & \frac{1}{2} I_{\mathrm{sc}}\left(h+l, t-\frac{(h+l)-z^{\prime}}{v}\right) \\
& -\rho_{\mathrm{top}} \frac{1}{2} I_{\mathrm{sc}}\left(h+l, t-\frac{l+z^{\prime}-h}{v}\right) \\
& +\frac{1}{2}\left(1+\rho_{\mathrm{top}}\right)\left(1-\rho_{\mathrm{top}}\right) \sum_{n=1}^{\infty} \rho_{\mathrm{top}}^{n-1} \rho_{\mathrm{bot}}^{n} I_{\mathrm{sc}} \\
& \times\left(h+l, t-\frac{l+z^{\prime}-h}{v}-\frac{2 n h}{c}\right)
\end{aligned}
$$

for $h \leq z^{\prime} \leq h+l$

(along the lightning channel below the junction point)

$$
\begin{aligned}
I\left(z^{\prime}, t\right)= & \frac{1}{2}\left(1-\rho_{\text {top }}\right) \\
& \sum_{n=0}^{\infty}\left[\rho_{\text {top }}^{n} \rho_{\text {bot }}^{n} I_{\mathrm{sc}}\left(h+l, t-\frac{l}{v}-\frac{h-z^{\prime}}{c}-\frac{2 n h}{c}\right)\right. \\
& \left.+\rho_{\text {top }}^{n} \rho_{\text {bot }}^{n+1} I_{\mathrm{sc}}\left(h+l, t-\frac{l}{v}-\frac{h+z^{\prime}}{c}-\frac{2 n h}{c}\right)\right]
\end{aligned}
$$

for $0 \leq z^{\prime} \leq h$ (along the strike object)

where $n$ is an index representing the successive multiple reflections occurring at the ends of the strike object and $v$ is the return-stroke wavefront speed that is equal to the current wave propagation speed along the TLs representing the lightning leader channels considered here [see Fig. 1(a)]. Note that $I_{\mathrm{sc}}$ in (2a)-(2c) is the lightning short-circuit current given by [8]

$$
I_{\mathrm{sc}}(h+l, t)=V_{0}(h+l, t) / Z_{\mathrm{ch}} .
$$

It is defined as the lightning current that would be measured at an ideally grounded object $\left(Z_{\text {gr }}=0\right.$ or $\left.Z_{\text {gr }} \ll Z_{\text {ch }}\right)$ having a negligible height $(h \approx 0)$, and launching an upward connecting leader of negligible length $(l \approx 0)$. This current represents lightning discharge regardless of the impedance "seen" by this discharge at its termination point, and therefore, can be used 
for comparison of lightning strikes to flat ground and to strike objects with or without upward connecting leaders.

\section{B. Lightning Strike to a Grounded Object Without an Upward Connecting Leader $(h \neq 0, l=0)$}

Currents at an arbitrary point $z^{\prime}$ along the lightning channel $\left(z^{\prime} \geq h\right)$, at the top of the object $\left(z^{\prime}=h\right)$, and along the strike object $\left(0 \leq z^{\prime} \leq h\right)$, all in the absence of an upward connecting leader, are given by the following three equations:

$$
\begin{aligned}
I\left(z^{\prime}, t\right)= & \frac{1}{2}\left(1-\rho_{\mathrm{top}}\right) I_{\mathrm{sc}}\left(h, t-\frac{z^{\prime}-h}{v}\right) \\
& +\frac{1}{2}\left(1+\rho_{\mathrm{top}}\right)\left(1-\rho_{\mathrm{top}}\right) \sum_{n=1}^{\infty} \rho_{\mathrm{top}}^{n-1} \rho_{\mathrm{bot}}^{n} I_{\mathrm{sc}} \\
& \times\left(h, t-\frac{z^{\prime}-h}{v}-\frac{2 n h}{c}\right)
\end{aligned}
$$

for $z^{\prime} \geq h \quad$ (along the lightning channel)

$$
\begin{aligned}
I(h, t)= & \frac{1}{2}\left(1-\rho_{\mathrm{top}}\right) I_{\mathrm{sc}}(h, t)+\frac{1}{2}\left(1+\rho_{\mathrm{top}}\right)\left(1-\rho_{\mathrm{top}}\right) \\
& \times \sum_{n=1}^{\infty} \rho_{\mathrm{top}}^{n-1} \rho_{\mathrm{bot}}^{n} I_{\mathrm{sc}}\left(h, t-\frac{2 n h}{c}\right)
\end{aligned}
$$

(at the top of the strike object)

$I\left(z^{\prime}, t\right)=\frac{1}{2}\left(1-\rho_{\mathrm{top}}\right) \sum_{n=0}^{\infty}\left[\begin{array}{c}\rho_{\mathrm{top}}^{n} \rho_{\mathrm{bot}}^{n} I_{\mathrm{sc}}\left(h, t-\frac{h-z^{\prime}}{c}-\frac{2 n h}{c}\right) \\ +\rho_{\mathrm{top}}^{n} \rho_{\mathrm{bot}}^{n+1} I_{\mathrm{sc}}\left(h, t-\frac{h+z^{\prime}}{c}-\frac{2 n h}{c}\right)\end{array}\right]$

for $0 \leq z^{\prime} \leq h$ (along the strike object).

It is clear from comparison of (4c) and (2c) that current waveforms along the strike object in the absence of upward connecting leader $(l=0)$ are identical to the corresponding current waveforms along the same strike object in the presence of an upward connecting leader $(l \neq 0)$, but shifted by $-l / v$ along the time axis. Note that $(4 \mathrm{a})-(4 \mathrm{c})$ are derived by setting $(l=0)$ in $(2 a)-(2 c)$, respectively.

\section{Lightning Strike to Flat Ground With an Upward Connecting Leader $(h=0, l \neq 0)$}

Currents at an arbitrary point $z^{\prime}$ along the lightning channel $\left(z^{\prime} \geq l\right)$ above the junction point between the descending and upward connecting leaders, along the lightning channel $(0 \leq$ $z^{\prime} \leq l$ ) below the junction point between the descending and upward connecting leaders, and at ground surface $\left(z^{\prime}=0\right)$, all in the absence of grounded strike object are given by the following three equations:

$$
\begin{aligned}
I\left(z^{\prime}, t\right)= & \frac{1}{2} I_{\mathrm{sc}}\left(l, t-\frac{z^{\prime}-l}{v}\right) \\
& +\frac{1}{2} \rho_{\mathrm{gr}} I_{\mathrm{sc}}\left(l, t-\frac{z^{\prime}-3 l}{v}\right) \\
& \text { for } \quad z^{\prime} \geq l
\end{aligned}
$$

(along the lightning channel above the junction point)

$$
\begin{aligned}
I\left(z^{\prime}, t\right)= & \frac{1}{2} I_{\mathrm{sc}}\left(l, t-\frac{l-z^{\prime}}{v}\right) \\
& +\frac{1}{2} \rho_{\mathrm{gr}} I_{\mathrm{sc}}\left(l, t-\frac{l+z^{\prime}}{v}\right)
\end{aligned}
$$

for $0 \leq z^{\prime} \leq l$

(along the lightning channel below the junction point)

$$
I(0, t)=\frac{1+\rho_{\mathrm{gr}}}{2} I_{\mathrm{sc}}\left(l, t-\frac{l}{v}\right)
$$

(at the ground surface)

where $\rho_{\mathrm{gr}}$ is the current reflection coefficient at the channel base (ground), which is expressed as

$$
\rho_{\mathrm{gr}}=\frac{\left(Z_{\mathrm{ch}}-Z_{\mathrm{gr}}\right)}{\left(Z_{\mathrm{ch}}+Z_{\mathrm{gr}}\right)} .
$$

Note that (5a)-(5c) are derived by setting $h=0$ in (2a)-(2c), respectively.

\section{Lightning Strike to Flat Ground Without an Upward Con- necting Leader $(h=0, l=0)$}

Current at an arbitrary point $z^{\prime}$ along the lightning channel $\left(z^{\prime} \geq 0\right)$ in the absence of both grounded strike object and upward connecting leader is given by the following equation:

$$
I\left(z^{\prime}, t\right)=\frac{1+\rho_{\mathrm{gr}}}{2} I_{\mathrm{sc}}\left(0, t-\frac{z^{\prime}}{v}\right)
$$

for $z^{\prime} \geq 0$ (along the lightning channel).

Note that (7a) is derived by setting both $h$ and $l$ in (2a) to zero. Current at the ground surface can be obtained from (7a) by setting $z^{\prime}=0$, which yields

$$
I(0, t)=\frac{1+\rho_{\mathrm{gr}}}{2} I_{\mathrm{sc}}(0, t) .
$$

(at the ground surface)

It is clear from comparison of $(5 c)$ and (7b) that the channelbase-current waveform in the absence of an upward connecting leader $(l=0)$ are identical to the corresponding current waveform in the presence of an upward connecting leader $(l \neq 0)$, but shifted by $-l / v$ along the time axis.

The total charge transfer to ground is the same regardless of the presence of strike object and/or an upward connecting leader. We have verified that time integrals from $t=0$ to $\infty$ of (2c) and (4c) at $z^{\prime}=0$, and of (5c) and (7b) are identical.

In the following, we will employ the model described earlier for the calculation of currents and fields for the case of 
subsequent stroke to examine their dependences on various factors. Subsequent strokes do involve upward connecting leaders, as reported by Wang et al. [13].

\section{LightNING RETURN-STROKE CURRENT}

In this section, using the TL model presented in Section II, we will investigate the influences of the presence of tall strike object and an upward connecting leader on the magnitude of lightning current. We assume that $\rho_{\mathrm{top}}=-0.5\left(Z_{\mathrm{ch}}=3 Z_{\mathrm{ob}}\right)$ and $\rho_{\mathrm{bot}}=$ $1\left(Z_{\mathrm{gr}}=0\right)$ in the case of lightning strike to a tall object, and $\rho_{\text {gr }}=1\left(Z_{\text {gr }}=0\right)$ in the case of lightning strike to a flat ground. Note that Janischewskyj et al. [14], from their analysis of five current waveforms measured at $474 \mathrm{~m}$ above ground on the 553-m-high $\mathrm{CN}$ Tower, inferred $\rho_{\text {top }}$ to vary from -0.27 to -0.49 , and Fuchs [15], from 13 simultaneous current measurements at the top and bottom of the 168-m-high Peissenberg Tower, found $\rho_{\text {top }}$ to vary from -0.39 to -0.68 . Also, Gorin and Shkilev [16], from measurements of lightning current at different points along the 540-m-high Ostankino Tower in Moscow, estimated the equivalent impedance of the lightning returnstroke channel to be in the range from 0.6 to $2.5 \mathrm{k} \Omega$, and Zundl [17] and Bermudez et al. [12] chose the characteristic impedance ranging from 200 to $300 \Omega$ for lossless TLs representing the Peissenberg Tower and the $\mathrm{CN}$ Tower, respectively, in order to reproduce the corresponding measured waveforms of lightning current at the tower top. Rakov et al. [18] showed that triggered lightning peak currents measured under a variety of grounding conditions ranging from nearly ideal to poor were similar, suggesting that for those measurements, $Z_{\text {gr }}$ was much smaller than $Z_{\mathrm{ch}}$. As stated in Section II-A, we assume that there is no impedance discontinuity at the junction point between the descending and upward connecting leaders. The value of return-stroke wavefront speed $v$ is set to $0.5 c$. We use for the lightning short-circuit current $I_{\mathrm{sc}}$ the current waveform proposed by Nucci et al. [19]. It is characterized by 10-to90\% rise-time of $\mathrm{RT}=0.15 \mu \mathrm{s}$, and thought to be typical for subsequent strokes. Additionally, we use a current waveform characterized by $\mathrm{RT}=1.4 \mu \mathrm{s}$. The height of the strike object is set to $h=100 \mathrm{~m}$, and the length of the upward connecting leader to $l=20 \mathrm{~m}$. Note that the length of the upward connecting leader initiated from ground or a short object in response to a descending dart leader in a subsequent stroke is expected to be of the order of $10 \mathrm{~m}$ or less [20].

Fig. 2 shows the waveforms of current at the channel base $\left(z^{\prime}=0\right)$ for lightning strikes to flat ground with and without a 20-m-long upward connecting leader for $\mathrm{RT}=0.15$ and $1.4 \mu \mathrm{s}$, calculated using (5c) and (7b). Fig. 3(a) shows waveforms of current at the top $\left(z^{\prime}=h\right)$ and bottom $\left(z^{\prime}=0\right)$ of a 100-m-high strike object with and without a 20-m-long upward connecting leader for RT $=0.15 \mu \mathrm{s}$, calculated using (2c) and (4c). Fig. 3(b) shows those for RT $=1.4 \mu \mathrm{s}$.

Calculated waveforms of fast- and slow-front lightning currents at the top of the tall object shown in Fig. 3(a) and (b) are in good agreement with waveforms of fast- and slow-front currents measured by Fuchs et al. [21] at the top of the Peissenberg Tower (fast-front current waveforms at the tower top measured

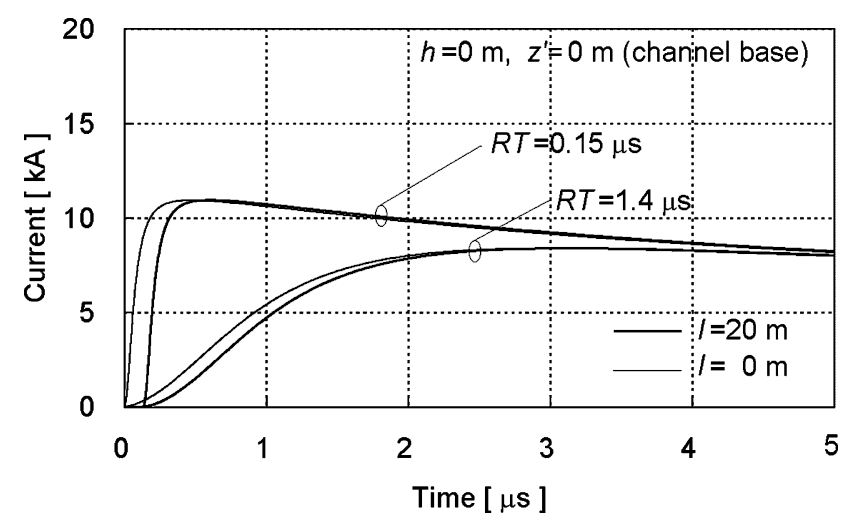

Fig. 2. Waveforms of current at the channel base $\left(z^{\prime}=0\right)$ for lightning strikes to flat ground with and without a 20-m-long upward connecting leader for $\mathrm{RT}=0.15$ and $1.4 \mu \mathrm{s}$.

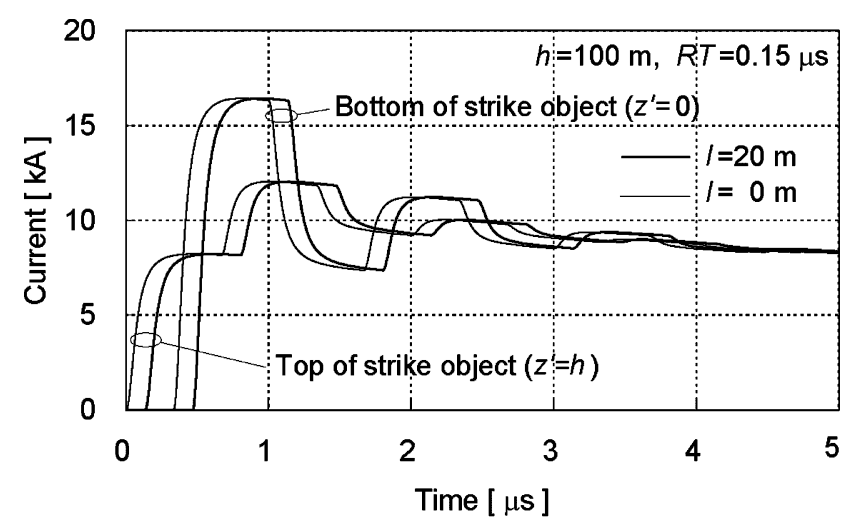

(a)

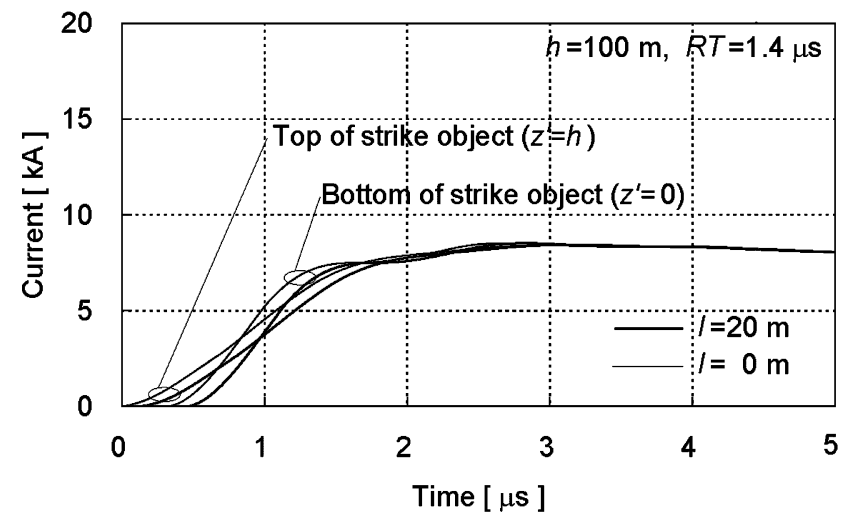

(b)

Fig. 3. Waveforms of current at the top $\left(z^{\prime}=h\right)$ and bottom $\left(z^{\prime}=0\right)$ of a 100-m-high strike object with and without a 20 -m-long upward connecting leader. (a) $\mathrm{RT}=0.15 \mu \mathrm{s}$. (b) $\mathrm{RT}=1.4 \mu \mathrm{s}$.

by Fuchs et al. show pronounced first reflections from ground, which cause about $40 \%$ increase in magnitude, while slow-front current waveforms measured at the tower top do not exhibit such a feature). Also, the calculated waveform of fast-front lightning current at the object top shown in Fig. 3(b) is similar to the waveform calculated using an antenna-theory model by Kordi et al. [22] (their calculated fast-front current waveform near the tower top of the simulated $\mathrm{CN}$ Tower includes a pronounced 
TABLE I

LightNing PEAK CURRENT (IN KILOAMPERES) AT THE TOP AND BotTOM OF A 100 -m-High STRIKe OBJeCT With $(l \neq 0)$ AND Without $(l=0)$ A 20-m-LONG UPWARD CONNECTING LEADER AND THOSE AT THE CHANNEL BASE FOR THE CASE OF THE SAME STRIKE TO FLAT GROUND

\begin{tabular}{r|c|c|c|c|c}
\hline \multirow{2}{*}{$h, \mathrm{~m}$} & \multirow{2}{*}{$l, \mathrm{~m}$} & \multicolumn{2}{|c|}{$R T=0.15 \mu \mathrm{s}$} & \multicolumn{2}{c}{$R T=1.4 \mu \mathrm{s}$} \\
\cline { 3 - 6 } & $\begin{array}{c}\text { Bottom } \\
\left(z^{\prime}=0\right)\end{array}$ & $\begin{array}{c}\text { Top } \\
\left(z^{\prime}=h\right)\end{array}$ & $\begin{array}{c}\text { Bottom } \\
\left(z^{\prime}=0\right)\end{array}$ & $\begin{array}{c}\text { Top } \\
\left(z^{\prime}=h\right)\end{array}$ \\
\hline 0 & 0 & 11.0 & 11.0 & 8.40 & 8.40 \\
0 & 20 & 11.0 & 11.0 & 8.40 & 8.40 \\
100 & 0 & 16.4 & 12.0 & 8.51 & 8.43 \\
100 & 20 & 16.4 & 12.0 & 8.51 & 8.43 \\
\hline
\end{tabular}

first reflection from the ground, which is about $50 \%$ increase in magnitude). Table I summarizes lightning peak current at the top and bottom of the strike object, and those at the channel base for lightning strikes to flat ground. Note that, as stated in Section II-B, current waveforms along the strike object in the absence of an upward connecting leader $(l=0)$ are identical to the corresponding current waveforms along the same strike object in the presence of an upward connecting leader $(l \neq 0)$, but shifted by $-l / v$ along the time axis. Also, as stated in Section II-D for the flat ground case, the channel-base-current waveform in the absence of an upward connecting leader is identical to the corresponding waveform in the presence of an upward connecting leader, but shifted by $-l / v$ along the time axis.

It is clear from Figs. 2 and 3 and Table I that the magnitude of lightning current at the bottom of the 100-m-high object is 1.5 times larger than that at the channel base due to the same strike to flat ground (16.4 kA versus $11 \mathrm{kA})$, regardless of the presence of a 20-m-long upward connecting leader, for a fastfront lightning current $(\mathrm{RT}=0.15 \mu \mathrm{s})$, while the magnitude of lightning current at the top of the strike object is not much different from that in the absence of the object (12 kA versus $11 \mathrm{kA}$ ). Our results for $\mathrm{RT}=0.15 \mu \mathrm{s}$ are consistent with previous findings of Rakov [23], who showed, using simple traveling wave calculations, that the magnitude of a fast-front lightning current at the top of a 70-m-high strike object was only $10 \%$ larger and at the bottom of the object was about $50 \%$ larger than that at the channel base for the case of the same strike to flat ground. He assumed that $Z_{\mathrm{ch}}=3 Z_{\mathrm{ob}}$ and $Z_{\mathrm{gr}}=0$ (corresponding current reflection coefficients were $\left.\rho_{\text {top }}=-0.5, \rho_{\text {bot }}=\rho_{\text {gr }}=0\right)$. Similarly, Melander [24] found from modeling that current peaks measured at the top of 70- and 40-m towers are essentially unaffected by the presence of the towers, while at the bottom of a 60-m tower, they are overestimated by a factor of about 1.6. In contrast, for lightning current with $\mathrm{RT}=1.4 \mu \mathrm{s}$, which is larger than the round-trip time of lightning current wave along the strike object $(2 h / c=0.67 \mu \mathrm{s})$, the current magnitude is not much influenced by the presence of either 100-m-long strike object or 20-m-long upward connecting leader.

\section{LIGHTNING ELECTRIC AND MAGNETIC FIELDS}

It is shown in Section III that the presence of a 100-m-high strike object influences the magnitude and waveform of lightning current much more significantly than that of a 20 -m-long

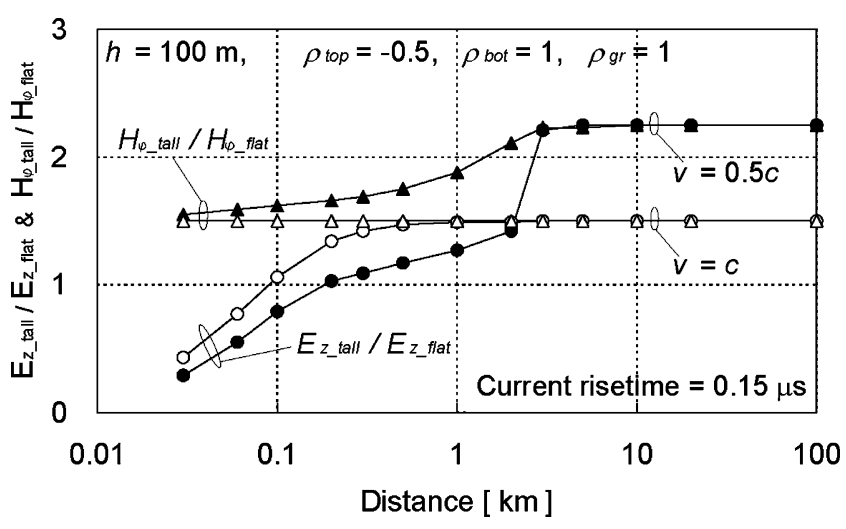

Fig. 4. Ratios $E_{z_{-} \text {tall }} / E_{z \_ \text {flat }}$ and $H_{\varphi \_ \text {tall }} / H_{\varphi \_ \text {flat }}$ as a function of horizontal distance $d$ from the lightning channel for two different lightning returnstroke speeds: (solid circles and triangles) $v=0.5 c$ and (hollow circles and triangles) $v=c$.

upward connecting leader. In this section, we will investigate the influences of the presence of a tall strike object for different return-stroke propagation speeds, current rise-times, and object heights on the vertical electric and azimuthal magnetic fields at ground level. In this sensitivity analysis, we assume that $\rho_{\text {top }}=$ $-0.5\left(Z_{\mathrm{ch}}=3 Z_{\mathrm{ob}}\right), \rho_{\mathrm{bot}}=1\left(Z_{\mathrm{gr}}=0\right)$, and $\rho_{\mathrm{gr}}=1\left(Z_{\mathrm{gr}}=\right.$ $0)$. Note that the electric and magnetic field waveforms (not shown in this paper) calculated for a lightning strike to a tall object using the TL model exhibit effects of successive reflections in the strike object (see, for example, [25] and [26]).

\section{A. Influence of Lightning Return-Stroke Propagation Speed}

In this section, we use the current waveform that is characterized by a $0 \%$ to $90 \%$ rise-time of $0.15 \mu \mathrm{s}$, and thought to be typical for subsequent strokes. Fig. 4 shows the ratios of vertical electric field on perfectly conducting ground for a lightning strike to a 100-m-high object ( $\left.E_{z_{-} \text {tall }}\right)$ at horizontal distances $d$ ranging from $30 \mathrm{~m}$ to $100 \mathrm{~km}$ and that for the same strike to flat ground $\left(E_{z_{-} \text {flat }}\right)$, for two values of return-stroke speed $v=0.5 c$ and $v=c$. Corresponding ratios for the azimuthal magnetic field $\left(H_{\varphi_{\text {_tall }}} / H_{\varphi_{\text {_flat }}}\right)$ are also shown in Fig. 4.

Ratios $E_{z_{-} \text {tall }} / E_{z_{\text {_flat }}}$ and $H_{\varphi_{\text {_tall }}} / H_{\varphi_{\text {_flat }}}$ increase with increasing $d$. For $v=0.5 c$ and $v=c, E_{z_{-} \text {tall }}$ is smaller than $E_{z \text { flat }}$ at $d$ ranging from 30 to $200 \mathrm{~m}$ and from 30 to $100 \mathrm{~m}$, respectively (vertical electric field is attenuated due to the presence of the $100-\mathrm{m}$-high object). $E_{z_{\text {_tall }}} / E_{z_{\text {_flat }}}$ for $v=0.5 \mathrm{c}$ is smaller than that for $v=c$ at $d$ ranging from $30 \mathrm{~m}$ to $2 \mathrm{~km}$ and larger at $d$ greater than $2 \mathrm{~km} . H_{\varphi_{-} \text {tall }} / H_{\varphi_{-} \text {flat }}$ for $v=0.5 c$ is always larger than that for $v=c$. The abrupt increase in $E_{z_{\text {_tall }}} / E_{z_{\text {_flat }}}$ between 2 and $3 \mathrm{~km}$ (see Fig. 4 ) is due to the fact that, for $d \leq 2 \mathrm{~km}$, both $E_{z_{-} \text {tall }}$ and $E_{z_{\text {_flat }}}$ rise to their peaks in several microseconds or more, while for $d>2 \mathrm{~km}$, the fields rise to their peaks in less than $1 \mu \mathrm{s}$ (because total electric field peak is essentially determined by the radiation field component at larger distances and by the electrostatic field component at smaller distances). Beyond $d=3 \mathrm{~km}$, both $E_{z_{-} \text {tall }} / E_{z_{-} \text {flat }}$ and $H_{\varphi \_ \text {tall }} / H_{\varphi \_ \text {flat }}$ attain values of 2.25 and 1.5 for $v=0.5 c$ and $v=c$, respectively. These are equal to the corresponding values of far-field enhancement factor $k_{\text {tall }}$, the equation for which is 


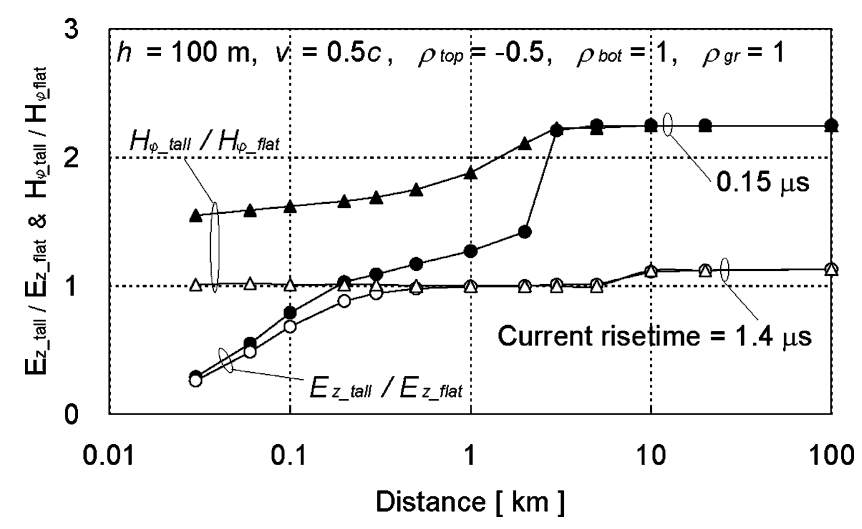

Fig. 5. Ratios $E_{z_{-} \text {tall }} / E_{z_{\text {_flat }}}$ and $H_{\varphi \_ \text {tall }} / H_{\varphi \_ \text {flat }}$ as a function of horizontal distance $d$ from the lightning channel for two different rise-times of lightning return-stroke current: (solid circles and triangles) $0.15 \mu \mathrm{s}$ and (hollow circles and triangles) $1.4 \mu \mathrm{s}$.

given by Baba and Rakov [25], and is reproduced here as

$$
k_{\text {tall }}=\frac{(1+c / v)\left(1-\rho_{\mathrm{top}}\right)}{\left(1+\rho_{\mathrm{gr}}\right)} .
$$

Note that (8) is valid only when the rise-time of injected lightning current is shorter than the propagation time from the top of the strike object to its bottom $h / c(=0.33 \mu \mathrm{s}$ for $h=100 \mathrm{~m})$.

The attenuation of vertical electric field in the vicinity of strike object observed in this study (see, Fig. 4) agrees with the trend reported from triggered lightning experiments by Fisher and Schnetzer [27], who measured triggered lightning electric fields at distances of 9.3 and $19.3 \mathrm{~m}$ from the base of a metallic strike rod whose height was either 4.5 or $11 \mathrm{~m}$, and found that a strike object appeared to reduce electric fields in its vicinity. The enhancement of vertical electric and azimuthal magnetic fields beyond 2 or $3 \mathrm{~km}$ from the lightning strike point due to the presence of a tall strike object is also in agreement with the trend reported by Bermudez et al. [28] from their simultaneous measurements of lightning current at the $\mathrm{CN}$ Tower and fields at distances of 2 and $17 \mathrm{~km}$.

\section{B. Influence of Lightning Return-Stroke Current Risetime}

Fig. 5 shows ratios $E_{z_{-} \text {tall }} / E_{z_{-} \text {flat }}$ and $H_{\varphi_{-} \text {tall }} / H_{\varphi_{-} \text {flat }}$ for two values of the 10 -to- $90 \%$ rise-time of the lightning returnstroke current, $\mathrm{RT}=0.15$ and $1.4 \mu \mathrm{s}$. The value of $v$ was set at $0.5 c$. The ratios increase with decreasing the rise-time of the lightning current. They approach 2.25 beyond $3 \mathrm{~km}$ and 1.13 beyond $10 \mathrm{~km}$ for rise-times equal to 0.15 and $1.4 \mu \mathrm{s}$, respectively. The former value (2.25) is equal to the far-field enhancement factor given by (8). Note that (8) is not applicable to the case of $1.4 \mu \mathrm{s}$, since this current rise-time is larger than $h / c=0.33 \mu \mathrm{s}$.

\section{Influence of Lightning Strike Object Height}

Fig. 6 shows ratios $E_{z_{-} \text {tall }} / E_{z_{-} \text {flat }}$ and $H_{\varphi_{-} \text {tall }} / H_{\varphi_{-} \text {flat }}$ at $d=$ $100 \mathrm{~m}, h$ ranging from $0-300 \mathrm{~m}$, and two values of lightning return-stroke current rise-time 0.15 and $1.4 \mu \mathrm{s}$. The value of $v$ was set at $0.5 c . H_{\varphi_{-} \text {tall }} / H_{\varphi_{-} \text {flat }}$ increases with increasing $h$,

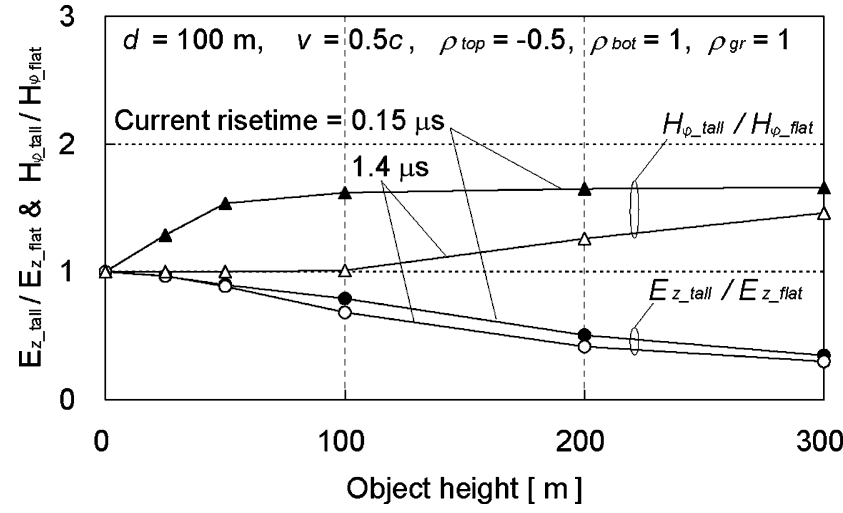

Fig. 6. Ratios $E_{z_{-} \text {tall }} / E_{z_{-} \mathrm{flat}}$ and $H_{\varphi_{-} \text {tall }} / H_{\varphi_{-} \mathrm{fl} \text { at }}$ at $d=100 \mathrm{~m}$ as a function of strike object of height $h$ for two different rise-times of lightning returnstroke current: (solid circles and triangles) $0.15 \mu \mathrm{s}$ and (hollow circles and triangles) $1.4 \mu \mathrm{s}$.

while $E_{z_{-} \text {tall }} / E_{z \_ \text {flat }}$ decreases with increasing $h$. Both ratios decrease with increasing rise-time of the lightning return-stroke current, the decrease for magnetic field being more pronounced than increase of electric field.

\section{CONCLUSION}

Using the TL model of the lightning return stroke generalized to include a tall grounded strike object and an electrically long upward connecting leader, we have investigated the influences of the presence of a tall strike object and an upward connecting leader on lightning currents and electromagnetic fields. The TL model employed allows a simple and self-consistent formulation of current both along the lightning channel and along the strike object, and the total charge transfer to the ground is the same regardless of the presence of a strike object and/or an upward connecting leader.

The presence of a 20-m-long upward connecting leader does not influence the magnitude and waveshape (only a shift along the time axis) of channel base current. For a typical subsequent return stroke, the lightning peak current at the bottom of a 100-m-high strike object is 1.5 times larger than the channel base peak current for the same strike to flat ground, regardless of the presence of a 20-m-long upward connecting leader, while the lightning peak current at the top of the strike object is not much different from the channel-base peak current in the absence of the strike object.

The vertical electric field due to a lightning strike to a 100-m-high object $E_{z_{-} \text {tall }}$ is reduced relative to that due to the same strike to flat ground $E_{z \text { flat }}$ at distances ranging from $30 \mathrm{~m}$ to $200 \mathrm{~m}$ from the object, and enhanced at distances greater than $200 \mathrm{~m}$. The azimuthal magnetic field for the tall object case $H_{\varphi_{-} \text {tall }}$ is larger than that for the flat ground case $H_{\varphi_{-} \text {flat }}$ at any distance. Ratios $E_{z_{-} \text {tall }} / E_{z_{\text {_flat }}}$ and $H_{\varphi \text { _tall }} / H_{\varphi \_ \text {flat }}$ increase with increasing distance and decreasing the rise-time of lightning current. Beyond some distance, $E_{z_{\text {_tall }}} / E_{z_{\text {fflat }}}$ becomes insensitive to distance change and equal to $H_{\varphi_{\text {_tall }}} / H_{\varphi_{\text {_fllat}}}$. At a distance of $100 \mathrm{~m}, E_{z_{-} \text {tall }} / E_{z_{-} \text {flat }}$ decreases, while $H_{\varphi_{-} \text {tall }} / H_{\varphi_{-} \text {flat }}$ increases with increasing the height of the object. 


\section{REFERENCES}

[1] H. Motoyama, W. Janischewskyj, A. M. Hussein, R. Rusan, W. A. Chisholm, and J.-S. Chang, "Electromagnetic field radiation model for lightning strokes to tall structures," IEEE Trans. Power Del., vol. 11, no. 3, pp. 1624-1632, Jul. 1996.

[2] S. Guerrieri, C. A. Nucci, F. Rachidi, and M. Rubinstein, "On the influence of elevated strike objects on directly measured and indirectly estimated lightning current," IEEE Trans. Power Del., vol. 13, no. 4, pp. 1543-1555, Oct. 1998.

[3] V. Shostak, W. Janischewskyj, A. M. Hussein, J.-S. Chang, and B. Kordi, "Return stroke current modeling of lightning striking a tall tower accounting for reflections within the growing channel and for upward-connecting discharges," in Proc. Int. Conf. Atmos. Elect., Gunterville, AL, 1999, pp. $123-126$.

[4] F. Rachidi, V. A. Rakov, C. A. Nucci, and J. L. Bermudez, "Effect of vertically extended strike object on the distribution of current along the lightning channel," J. Geophys. Res, vol. 107, no. D23, pp. 4699-1-46996, 2002 DOI: 10.1029/2002JD002119.

[5] J. L. Bermudez, M. Rubinstein, F. Rachidi, F. Heidler, and M. Paolone, "Determination of reflection coefficients at the top and bottom of elevated strike objects struck by lightning," J. Geophys. Res., vol. 108, no. D14, pp. 4413-1-4413-13, 2003 DOI: 10.1029/2002JD002973.

[6] D. Pavanello, F. Rachidi, M. Rubinstein, J. L. Bermudez, and C. A. Nucci, "Electromagnetic field radiated by lightning to tall towers: Treatment of the discontinuity at the return stroke wave front," $J$ Geophys. Res., vol. 109, no. D6, pp. DO6114-1-D06114-7, 2004 DOI: 10.1029/2003JD004185.

[7] S. Miyazaki and M. Ishii, "Influence of elevated stricken object on lightning return-stroke current and associated fields," in Proc. 27th Int. Conf. Lightning Protection, Avignon, France, Sep. 2004, pp. 122-127.

[8] Y. Baba and V. A. Rakov, "On the use of lumped sources in lightning return stroke models," J. Geophys. Res., vol. 110, no. D3, pp. D03101-1D03101-10, Feb. 2005 DOI:10.1029/2004JD005202.

[9] Y. Baba and V. A. Rakov, "Transmission line model of lightning return strokes generalized to include a tall grounded strike object and an upward connecting leader," paper presented at the 17th Int. Zurich Symp. Electromagn. Compat., W4-Light-1-1, Singapore, Feb./Mar. 2006.

[10] Y. Baba and V. A. Rakov, "On the interpretation of ground reflections observed in small-scale experiments simulating lightning strikes to towers," IEEE Trans. Electromagn. Compat., vol. 47, no. 3, pp. 533-542, Aug. 2005.

[11] Y. Baba and V. A. Rakov, "On the mechanism of attenuation of current waves propagating along a vertical perfectly conducting wire above ground: Application to lightning," IEEE Trans. Electromagn. Compat., vol. 47, no. 3, pp. 521-532, Aug. 2005.

[12] J. L. Bermudez, F. Rachidi, W. A. Chisholm, M. Rubinstein, W. Janischewskyj, A. M. Hussein, V. Shostak, and J. S. Chang, "On the use of transmission line theory to represent a nonuniform verticallyextended object struck by lightning," in Proc. IEEE Symp. Electromagn. Compat., Boston, MA, Aug. 2003, pp. 501-504.

[13] D. Wang, V. A. Rakov, M. A. Uman, N. Takagi, T. Watanabe, D. Crawford, K. J. Rambo, G. H. Schnetzer, R. J. Fisher, and Z.-I. Kawasaki, "Attachment process in rocket-triggered lightning strokes," J. Geophys. Res., vol. 104, no. D2, pp. 2141-2150, Jan. 1999.

[14] W. Janischewskyj, V. Shostak, J. Barratt, A. M. Hussein, R. Rusan, and J.-S. Chang, "Collection and use of lightning return stroke parameters taking into account characteristics of the struck object," in Proc. 23 rd Int. Conf. Lightning Protection, Florence, Italy, 1996, pp. 16-23.

[15] F. Fuchs, "On the transient behaviour of the telecommunication tower at the mountain Hoher Peissenberg," in Proc. 24th Int. Conf. Lightning Protection, Birminghan, U.K., 1998, pp. 36-41.

[16] B. N. Gorin and A. V. Shkilev, "Measurements of lightning currents at the Ostankino tower," (in Russian), Electrichestrvo, vol. 8, pp. 64-65, 1984.

[17] T. Zundl, "Lightning current and LEMP calculations compared to measurements gained at the Peissenberg tower," paper presented at the 22th Int. Conf. Lightning Protection, Budapest, Hungary, Sep. 1994, Paper R 1 c-08.

[18] V. A. Rakov, M. A. Uman, K. J. Rambo, M. I. Fernandez, R. J. Fisher, G. H. Schnetzer, R. Thottappillil, A. Eybert-Berard, J. P. Berlandis, P. Lalande, A. Bonamy, P. Laroche, and A. Bondiou-Clergerie, "New insights into lightning processes gained from triggered-lightning experiments in Florida and Alabama," J. Geophys. Res., vol. 103, no. D12, pp. $14117-14139,1998$.

[19] C. A. Nucci, G. Diendorfer, M. A. Uman, F. Rachidi, M. Ianoz, and C. Mazzetti, "Lightning return stroke current models with specified channel-base current: A review and comparison," J. Geophys. Res., vol. 95, no. D12, pp. 20 395-20 408, 1990.

[20] V. A. Rakov and M. A. Uman, Lightning: Physics and Effects. Cambridge, U.K.: Cambridge Univ. Press, 2003.

[21] F. Fuchs, E. U. Landers, R. Schmid, and J. Wiesinger, "Lightning current and magnetic field parameters caused by lightning strikes to tall structures relating to interference of electronic systems," IEEE Trans. Electromagn. Compat, vol. 40, no. 4, pp. 444-451, Nov. 1998.

[22] B. Kordi, R. Moini, W. Janischewskyj, A. M. Hussein, V. O. Shostak, and V. A. Rakov, "Application of the antenna theory model to a tall tower struck by lightning," J. Geophys. Res., vol. 108, no. D17, pp. 4542-14542-9, Sep. 2003 DOI:10.1029/2003JD003398.

[23] V. A. Rakov, "A review of the interaction of lightning with tall objects," Recent Res. Dev. Geophys., vol. 5, pp. 57-71, 2003.

[24] B. G. Melander, "Effects of tower characteristics on lightning arc measurements," in Proc. Int. Conf. Lightning Static Elect., Orlando, FL, pp. 34/134/12, 1984.

[25] Y. Baba and V. A. Rakov, "Lightning electromagnetic environment in the presence of a tall grounded strike object," J. Geophys. Res., vol. 110, no. D9, pp. D09108-1-D09108-18, May 2005 DOI:10.1029/2004JD005505.

[26] E. P. Krider, S. Guerrieri, F. Napolitano, C. A. Nucci, M. Paolone, F. Rachidi, and V. A. Rakov, "Effect of traveling-waves of current on the electromagnetic response of a tall Franklin rod considering various lightning return stroke models," in Proc. 28th Int. Conf. Lightning Protection, Kanazawa, Japan, Sep. 2006, no. I-44, pp. 273-278.

[27] R. J. Fisher and G. H. Schnetzer, "1993 triggered lightning test program: Environments within 20 meters of the lightning channel and small area temporary protection concepts," Sandia Nat. Lab., Albuquerque, NM, Rep. SAND94-0311/UC-706, 1994.

[28] J. L. Bermudez, F. Rachidi, M. Rubinstein, W. Janischewskyj, V. O. Shostak, D. Pavanello, J. S. Chang, A. M. Hussein, C. A. Nucci, and M. Paolone, "Far-field-current relationship based on the TL model for lightning return strokes to elevated strike objects," IEEE Trans. Electromagn. Compat., vol. 47, no. 1, pp. 146-159, Feb. 2005.

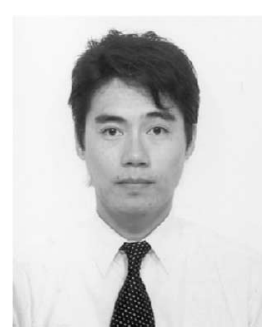

Yoshihiro Baba (S'95-M'99) received the B.S., M.S., and Ph.D. degrees in electrical engineering from the University of Tokyo, Tokyo, Japan, in 1994, 1996, and 1999, respectively.

He is currently an Associate Professor in the Department of Electrical Engineering, Doshisha University, Kyoto, Japan. From April 2003 to August 2004, he was a Visiting Scholar in the University of Florida, Gainesville, on sabbatical leave from Doshisha University. He is the author or coauthor of over 20 papers published in reviewed journals.

Dr. Baba is a member of the American Geophysical Union and the Institution of Engineering and Technology.

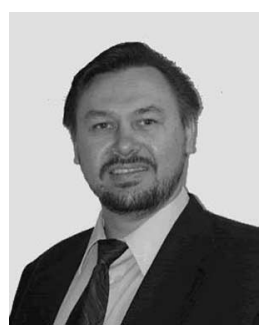

Vladimir A. Rakov (SM'96-F'03) received the M.S. degree in electrical engineering and the Ph.D. degree in (high voltage engineering) from Tomsk Polytechnical University (Tomsk Polytechnic), Tomsk, Russia, in 1977 and 1983, respectively.

He is currently a Professor in the Department of Electrical and Computer Engineering, University of Florida (UF), Gainesville, and the Co-Director of the International Center for Lightning Research and Testing (ICLRT). He is the author or coauthor of one book, over 30 patents, and over 400 papers and technical reports on various aspects of lightning, with over 140 papers being published in reviewed journals. From 1977 to 1979, he was an Assistant Professor of electrical engineering at Tomsk Polytechnic, where, in 1978, he became involved in lightning research at the High Voltage Research Institute, and, from 1984 to 1994 he was the Director of the Lightning Research Laboratory.

Dr. Rakov is the Chairman of the Technical Committee on Lightning of the Biennial International Zurich Symposium on Electromagnetic Compatibility and former Chairman of the American Geophysical Union (AGU) Committee on Atmospheric and Space Electricity. He is also a Fellow of the American Meteorological Society and the Institution of Engineering and Technology, and a member of AGU, the Society of Automotive Engineers, and the American Society for Engineering Education. 